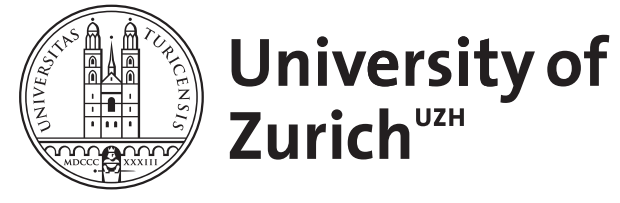
Archive

University of Zurich

University Library

Strickhofstrasse 39

CH-8057 Zurich

www.zora.uzh.ch

Year: 2014

\title{
Epidemiology of fishborne trematodiasis in Kazakhstan
}

Sultanov, A ; et al ; Torgerson, P R

DOI: https://doi.org/10.1016/j.actatropica.2014.04.030

Posted at the Zurich Open Repository and Archive, University of Zurich

ZORA URL: https://doi.org/10.5167/uzh-97929

Journal Article

Accepted Version

Originally published at:

Sultanov, A; et al; Torgerson, P R (2014). Epidemiology of fishborne trematodiasis in Kazakhstan. Acta Tropica, 138:60-66.

DOI: https://doi.org/10.1016/j.actatropica.2014.04.030 


\section{Epidemiology of Fish Borne Trematodiasis in Kazakhstan.}

A. Sultanov ${ }^{1}$, A. Abdybekova ${ }^{1}$, A Abdibaeva $^{1}$, Z. Shapiyeva ${ }^{2}$, T. Eshmuratov ${ }^{3}$ P.R. Torgerson ${ }^{4 *}$

${ }^{1}$ Kazakh State Veterinary Research Institute, Almaty, Kazakhstan

${ }^{2}$ Scientific-Practical Centre for Sanitary-Epidemiological Expertise and Monitoring, Almaty,

Kazakhstan

${ }^{3}$ National Scientific Center of Surgery, Almaty, Kazakhstan.

${ }^{4}$ Section of Epidemiology, Vetsuisse Faculty, University of Zürich, Switzerland

*Corresponding author: paul.torgerson@acces.uzh.ch

Keywords: Opithorchis, food born trematodes, epidemiology, Zoonosis, Kazakhstan 


\begin{abstract}
Fish borne trematodes are an important cause of morbidity in Kazakhstan. The number of human cases of opisthorchiidosis (infection with parasites of the family opisthorchiidae) reached a peak of 2521 recorded cases (17 cases per 100,000) in 2002 with a gradual decline to 1225 cases $(7.4$ cases per 100,000) in 2011. Most human cases are found in the north and north east part of Kazakhstan in areas drained by the Irtysh River and it tributaries. A further focus is found in the north west in the Ural river basin in the European part of Kazakhstan. The most common occupations of patients with opisthorchiidosis included the manual labourers, those employed in the home or unemployed. Necropsy investigations of village dogs in an endemic region revealed 37 of 51 (72\%) village dogs infected with either Opithorchis felineus or Methorchis bilis. Likewise an investigation of 242 cats consisting of strays, village, suburban and city cats revealed $79(33 \%)$ animals infected with $O$. felineus. Higher prevalences were seen in strays and village cats compared to suburban cats. No urban cats, which lived in apartments, were found to be infected. Other important zoonoses included Echinococcus granulosus, detected in 2 of the 51 necropsied village dogs and E. multilocularis was found in 2 out of 124 necropsied stray cats. Investigations of locally caught fish revealed 10 of 107 (9\%) roach (Rutilus rutilus), 49 of 68(72\%) ide (Leuciscus idus) and 2 of 79 (2.5\%) bream (Abramis brama) infested with trematode metacercariae. No metacercariae were found in 609 crucian carp (Carassius carassius), 35 tench (Tinca tinca), 79 carp (Cyprinus carpio), 46 perch (Perca fluviatilis) or 20 zander (Sander lucioperca).
\end{abstract}




\section{Introduction}

Food borne trematodes are a number of parasitic species transmitted by the consumption of undercooked, usually aquatic products. (Keiser and Utzinger, 2009) and infections with such trematodes cause a high global burden of disease. Over 56 million people are infected with food borne trematodes, 7.9 million with severe sequelae. Over 7000 deaths per year can be attributable to infection with foodborne trematodes (Fürst et al., 2012). The Wold Health Organization also recognises food borne trematode infections as a neglected tropical disease (World Health Organization, 2010)

Kazakhstan is the largest landlocked country in the world with the western most district being geographically part of Europe and eastern districts bordering China. The country has an area of 2.7 million square kilometers and a population of approximately 17 million, of which $46 \%$ is rural, and population density of 5.9 per $\mathrm{km}^{2}$. Agriculture represents $5 \%$ of economic output. The climate is continental, with warm summers and colder winters. Precipitation varies between arid and semi-arid conditions.

Opisthorchis felineus is known to be endemic in the new independent states of the former Soviet Union ( Ilyinskikh , 2002; Kochetkov et al., 2010; Syskova et al., 2001:). The first intermediate hosts of $O$. felineus are species of freshwater snails from the genus Bithynia ( Brusentsov et al., 2013; Mordvinov et al., 2012). Fish of the Cyprinidae family serve as the second intermediate hosts (Pozio et al., 2013). Metacercariae, the encysted and resting stage of a fluke larva, accumulate in muscles of susceptible fish. When final hosts ingest raw fish, the young trematode escapes from the metacercarial cyst and migrates through the common bile duct into the bile duct and gall bladder, where it develops into an adult. Mature flukes live in the liver of definitive hosts (fish-eating mammals, including humans). Human infections occur by consuming raw or undercooked fish infested with metacercariae.

O. felineus affects 1.6 million people (Yossepowitch et al., 2004). In humans, acute $O$ 
felineus infection may result in hepatitis-like symptoms including fever . abdominal pain, nausea and emesis. In chronic infections, inflammation, fibrosis and obstruction of the biliary tract, liver abscesses, pancreatitis and supperative cholangitis may occur (Keiser and Utzinger, 2009). The carcinogenicity of chronic $O$. felineus infections is yet to be proven. However, available epidemiological and clinical data in humans and animals suggest that $O$. felineus can be the cause of neoplasia. There is a clear increase in the incidence cholangiocarcinoma in endemic areas of Siberia. In Russia, the highest incidence of bile duct cancer in humans was documented in the same area (i.e., Tyumen Region) with the highest incidence of $O$. felineus infection in humans (Mordvinov et al., 2012) and a previous estimates of the health impact of this parasite have assumed that infection carries the same relative risk of carcinogenesis as O. viverrini infection (Parkin, 2006).

The parasite has been reported to be endemic in Aktobe, Karadanda, Pavlodar, Akmola and Kostanay districts (World Health Organization, 1995). Wild caught fish are commonly consumed raw or slightly salted. Consequently, there have previously been a number of reports in the Russian literature on opithorchosis in humans, dogs and cats. Pantiukhov and Vinogradova (1963) described up to $100 \%$ of cats and $70 \%$ of dogs infected in the Pavlodar and Semipalatinsk regions. In addition there were a large number of human cases of infection diagnosed in Pavlodar which were associated with the habit of eating salted dried fish. In some villages along the Irtysh river human prevalences of $42 \%$ have been recorded in the past (Terentyeva 1985) and Zhumabekova and Kamyeshyeva (2008) reported that the annual incidence of human opithorchosis had increased from under 10 per 100,000 to over 140 per 100,000 between 1995 and 2006 in the Kashir district (population 21,000). Studies of fish from the Irgiz and Turgay river basins have previously found the prevalence of infection in ide of up to 50\% (Khokhalkova 1957). Older data has indicated foci of opithorchosis in the Karaganda and Tamirtau regions (Kreptogorskoy 1932). More recently there is a report of $4.5 \%$ of Prussian carp (Carassius gibelio) recovered from the Baikon lakes, Kashir district in the Pavoldar Oblast in north Easter Kazakhstan were infected with metacercariae of Opithorchis felineus 
(Zhumabekova and Kamyeshyeva 2008).

The objective of this study was to report the incidence of infection in humans in Kazakhstan. This study reports the numbers of officially reported cases of human opisthorchiidosis in Kazakhstan between 1997 and 2011 and analyses the trends in the disease. We also give details of the geographical origin and occupations of cases since 2007. Therefore a second objective to this study was to investigate the prevalence of zoonotic trematodes in potential definitive and intermediate hosts in one of these endemic districts, namely Akmola district. Consequently, we report surveillance results from domestic definitive and intermediate hosts of $O$. felineus from the northern part of Kazakhstan.

\section{Materials and Methods}

\section{Human data}

Human faceal samples are supplied by patients who are suspected clinical cases of opisthorchiidosis (or indeed possibly other diseases) and the samples submitted to regional diagnostic laboratories by the patients' phycisian between 1997 and 2011. The Kato-Katz technique and/or the ether sedminetation technique (as described by WHO 1991) was used for routine diagnosis of human helminthoses.All data is sent to the Scientific Practical Center of Sanitary and Epidemiological Expertise and Monitoring, Almaty. From these records data human opisthorchiidosis are reported together with details of the origin of the case and occupation.

\section{Dogs}

A total of 51 dogs from villages were necropsied from rural areas of Akmola district. These dogs were from a village environment and euthanised at the request of their owners and hence were a convenience sample. All helminth parasites were removed from the gastrointestinal tract and liver 
and identified morphologically, with the use of microscopy where necessary. The bile ducts were incised specifically to find any infection with hepatic trematodes. Total parasite counts of each species identified were recorded.

\section{Cats}

We undertook necropsy of 242 cats from rural areas of Akmola district and from Astana. Astana, the capital of Kazakhstan is completely surrounded by Akmola district. These cats were urban cats living in apartments $(n=56)$, suburban cats $(n=85)$, village cats $(n=128)$ or stray cats $(n=72)$. All cats were humanely euthanised by the request of their owner, and were also inevitably a convenience sample. All helminth parasites were recovered from the gastrointestinal tract and liver and identified.

\section{Fish}

In total we investigated 1043 specimens of freshwater fish representing 8 species. Fish were purchased from various markets and shops in Astana or Akmola district, or caught directly from the Korgaldjin lakes (also in the Akmola district). The species of freshwater fish examined were carp (Cyprinus carpio), crucian carp (Carassius carassius), roach (Rutilus rutilus), tench (Tinca tinca), ide (Leuciscus idus), rudd (Scardinius erythropthalmus), bream (Abramis brama), perch (Perca fluviatilis) and zander (Sander lucioperca). Visual inspection and microscopy was performed to the internal organs of the body cavity, the eye and the edible parts of the fish's body (muscles). The skin was separated from underlying subcutaneous tissue. Thin layers of muscle of no more than 2-3mm thickness were scraped off with a sharp scalpel or cut and squeezed between glass slides and examined microscopically. To identify the larval stages of the parasites in the muscles of fish examined by the compressor. The parasites in fish were identified microscopically according to 
Bayer and Shulman (1984).

The studies on dogs, cats and fish were undertaken between 2008 and 2010.

\section{Statistical Analysis}

Trends in the numbers of human cases were examined by $\chi^{2}$ for trend. Abundances and prevalences and their confidence intervals were examined by generalized linear models using R (R Core Team, 2013) .

\section{Ethical statement}

All euthanised animals were at the specific request of their owners with a further request to dispose of the animal carcass with permission given for collection of any relavent smaples for surveillance purposes. All human data was from routine collected surveillance data and anonymised so that no individual patient details can be identified.

\section{Results}

\section{Human cases}

The numbers of cases of human opisthorchiidosis (ie the of patients from which opisthorchiid type eggs were isolated) ranged from a maximum of 2521 (annual incidence of 17 cases per 100,000) in 2002 to a minimum of 1225 (7.4 cases per 100,000) in 2011. There is a clear trend after 2002 with a declining number of cases $\left(\chi^{2}\right.$ for trend, $\left.\mathrm{p}<0.001\right)$ (figure 1 ). Nearly all cased are in the north of the country with a particularly high incidence seen in Pavlodar District in the north east of the country (figure 2). There was also a focus in the European part of Kazakhstan in the west Kazakhstan district. Patients had a variety of occupations, but with many cases being in people who were not 
employed or worked in the home or as manual labourers (figure 3). For the years 2006-2011 there was also data available for the numbers of cases in children 14 years or under. This varied from 69 of 1252 cases $(5.5 \%)$ in 2010 to 124 of 1525 cases in 2008. Although there was some variation in the proportion of cases that were children, there was no significant trend over this 6 year period ( $\chi^{2}$ for trend, $\mathrm{p}=0.15)$.

Dogs

Table 1 summarizes the parasites recovered from the necropsy of 51 village dogs. O. felineus was recovered from 35 dogs with a mean abundance of 30 parasites per dog (Table 1). Two dogs were infected with single specimens of Methorchis bilis. Of further note is that 2 dogs were also infected with Echinococcus granulosus. All parasites in dogs had an oversidepersed distribution regardless of diagnostic method, except Taenia spp, which appeared to be randomly (Poisson) distributed.

Cats

O. felineus was found in village, suburban and stray cats, but not in cats confined to apartments (Table 2). Village cats had the highest prevalence with 44 of 65 cats infected (68\%). This was significantly higher than either stray cats or suburban cats (Fisher test $\mathrm{p}<0.001$ ), with no difference between the latter two groups having $24 \%$ and $20 \%$ prevalences respectively. Two stray cats were found to be infected with E. multilocularis.

\section{Fish}

Three species of freshwater fish were found to be infected with Opisthorchiidae spp (Table 3). A total of 49 Ide (Leuciscus idus) out of 68 examined (72\%) were infected. In contrast just 10 of 107 roach (Rutilus rutilus) and 2 of 79 bream (Abramis brama) were infected. 


\section{Discussion}

This study indicates that human opithorchiidosis is an important public health issue in the north of Kazakhstan, although the data indicates a slowly declining trend in the numbers of reported cases. Most human cases were seen in the northern and northeastern regions which are drained by the River Irtysh and its tributaries the Ishim and Tobal Rivers. A further focus was seen in the northwest of the country which is drained by the Ural River, considered to be the Europe-Asia boundary. This report gives further important information on the epidemiology of fish borne trematodes in Kazakhstan in addition to that previously reported in the Russian literature. Information regarding the detailed clinical symptomatology, such as duration or presenting signs, of the patients from which samples were taken is unavailable. It is possible that some of the cases were incidental findings when the referring physician suspected other disease. However, the referring physician is likely to have instigated appropriate treatment for trematodiasis on receipt of the laboratory report. Nevertheless, regardless of the reason the referring physicians submitted the faecal samples, the data gives the annual incidence of laboratory confirmed cases of opisthorchiidosis in Kazakhstan.

The study in fish indicates infection of locally caught freshwater fish is common with the ide in particular having a high prevalence, with roach and bream also being infected. In Siberia, ide, roach, belica (Leucaspius delineatus), bream, dace and minnow (subfamily Leuciscinae) are known to be suitable intermediate hosts of Opisthorchiidae (Karpenkon et al., 2008; Mordvinov et al., 2012), with ide and belica predominating with prevalences of over $40 \%$ in some localities. In contrast in a recent study in Italy, the only species of fish found to be infected was the tench (De Liberato et al., 2011) which was not found to be infected in the present study.

Village dogs have a high prevalence of infection with $O$. felineus and could be infected from 
the same fish that are infecting humans. This is also true of rural cats. Suburban, village and stray cats were all infected with O. felineus. Village cats had the highest prevalence - approaching 68\% whilst village dogs had a prevalence of $69 \%$. Urban cats in contrast had no infection and thus may have less access to raw fish. The contribution of domestic carnivores in maintaining the cycle is unknown. It is possible that faeces from infected cats and dogs contaminate water courses allowing infection of the first intermediate host. This would then allow onward transmission to fish and hence to humans. Previous reports have indicated that cats and dogs are frequent definitive hosts in Siberia (Mordvinov et al., 2012) which is consistent with our findings. In particular prevalences of $61.5 \%$ have been reported in cats and $11.6 \%$ of dogs from settlements along the Irtysh River in south west Siberia (Karpenkon et al., 2008). However a number of wild carnivores such as foxes (Schuster et al., 1999) mink (Shimalov and Shimalov, 2001) otter (Shimalov et al., 2000) pig and other mammals (Mordvinov et al., 2012) are also suitable definitive hosts. Transmission of fish borne trematodes appears to be density independent (Boerlage et al., 2014) and thus it is difficult to come to conclusions about the relative contributions of different hosts species for transmission. In Italy the only definitive host found to be infected were domestic cats during an investigation following an outbreak of human opithorchosis in central Italy (De Liberato et al., 2011)

The necropsy studies confirmed that the main trematode infecting dogs and cats in this regions was O. felineus, with two specimens of Methorchis bilis recovered from dogs. Coprological studies based on egg identification only are not able to distinguish between these two species and it is known that both species are endemic across much of this region (Mordvinov et al., 2012). As the infections in humans were made by morphology of eggs in the faecal samples, it is not possible to confirm whether the human Opisthorchiidosis were due to O. felineus or M. bilis Furthermore, it is not possible to rule out the presence of intestinal flukes as they are frequently misdiagnosed as Opithorchis spp due to similaries in egg morphology (see for example Chai et al, 2013). However, small intestinal flukes were not observed in the necropsy studies of dogs and cats despite the careful 
examination of the intestines necessary to demonstrate the presence of the small Echinococcus spp. In neighbouring Siberia it is believed that many cases of human cases of Opisthorchiidosis may be caused by M. bilis and possibly other trematodes in addition to $O$. felineus (Karpenkon et al., 2008). Likewise the metacercariae of the two species are morphologically indistinguishable (Mordvinov et al., 2012) and thus the fish examined could have been infected by either parasite. Nevertheless, the public health data and the study on domestic definitive hosts and freshwater fish used for human consumption indicate that there is major transmission of fish borne trematodes in this region of Kazakhstan which has an impact on human health burden.

There appears to be a trends in the decrease in the numbers of reported human cases. With the available data it is only possible to speculate as to the reasons for this. Kazakhstan has one of the fastest growing economies in the world so a rapid improvement in living standards and improvements in government public health services are likely to decrease the incidence of any transmissible disease.

In neighboring regions of Russia human infection has been described in several studies. In the Tomsk region annual incidence of disease increased from 495 per 100,000 to 649 per 100,000 between 1997 and 2006 (Mordvinov et al., 2012). Surveillance data in Tomsk Oblast has also indicated a high prevalence of infection with over $11 \%$ of urban inhabitant and $32 \%$ of rural inhabitants infected (Orgorodova et al. 2007). In other areas of Siberia such as Irkutsk region the incidence appears to be somewhat lower and stable at about 3.4 cases per 100,000 per year between 2001 and 2011 (Kupriyanova and Timoshenko, 2012)

This study also illustrates that dogs from this region have a low prevalence of E. granulosus and is consistent with fewer human cases of CE are seen in northern Kazakhstan compared to southern or western districts. (Torgerson et al., 2002). E.multilocularis was also isolated from two cats. Although cats have been reported previously to be infected with this parasite (for example Petavy et al., 2000), experimentally they appear to be poor hosts and hence are unlikely to make any 
significant contribution to transmission (Kapel et al., 2006).

\section{References}

Bayer, O. N. and Shulman, S. S. , 1984. [Key to parasites of freshwater fish fauna of the USSR. Leningrad: Nauka, 1987. - 583 p.] (in Russian)

Boerlage, A. S., Graat, E. A. M., Verreth, J. A., de Jong, M. C. M., 2014. Transmission of fish-borne zoonotic trematodes (Heterophyidae) to common carp (Cyprinus carpio) is independent of density of fish and trematodes. J. Helminthol. 88, 183-188.

Brusentsov, I.I., Katokhin, A.V., Brusentsova, I.V., Shekhovtsov, S.V., Borovikov, S.N., Goncharenko, G.G., Lider, L.A., Romashov, B.V., Rusinek, O.T., Shibitov, S.K., Suleymanov, M.M., Yevtushenko, A.V., Mordvinov, V.A., 2013. Low Genetic Diversity in Wide-Spread Eurasian Liver Fluke Opisthorchis felineus Suggests Special Demographic History of This Trematode Species. PLoS ONE 8, e62453.

Chai, J.-Y., Yong, T.-S., Eom, K.S., Min, D.-Y., Jeon, H.-K., Kim, T.-Y., Jung, B.-K., Sisabath, L., Insisiengmay, B., Phommasack, B., Rim, H.-J., 2013. Hyperendemicity of Haplorchis taichui infection among riparian people in Saravane and Champasak province, Lao PDR. Korean J. Parasitol. 51, 305-311.

De Liberato, C., Scaramozzino, P., Brozzi, A., Lorenzetti, R., Di Cave, D., Martini, E., Lucangeli, C., Pozio, E., Berrilli, F., Bossù, T., 2011. Investigation on Opisthorchis felineus occurrence and life cycle in Italy. Vet. Parasitol. 177, 67-71.

Fürst, T., Keiser, J., Utzinger, J., 2012. Global burden of human food-borne trematodiasis: a systematic review and meta-analysis. Lancet Infect. Dis. 12, 210-221.

Ilyinskikh E.N., 2002. Actual issues of studying of opisthorchiasis in Siberia. Bull. Sib. Med. 1, 6370.

Kapel, C.M.O., Torgerson, P.R., Thompson, R.C.A., Deplazes, P., 2006. Reproductive potential of 
Echinococcus multilocularis in experimentally infected foxes, dogs, raccoon dogs and cats. Int. J. Parasitol. 36, 79-86.

Karpenkon, S.V., Chechulin, A.I., Yurlova, N.I., Serbina, E.A., Vodyanitskaya, S.N., Krvopalov, A.V., Fedorov, K.P., 2008. Characteristics of Opisthorchiasis foci in south west Siberia. Contemp. Probl. Ecol. 1, 517-521.

Keiser, J., Utzinger, J., 2009. Food-borne trematodiases. Clin. Microbiol. Rev. 22, 466-483.

Khokhalkova, N. A. (1957) Results of the five year fight against helminths in the Kazakh Soviet Socialist Republic and the prospects for the improvement of helminthoses. Abstracts of the Congress for Health Care Workers of Kazakhstan. Alamty, pp 54-60. [in Russian]

Kochetkov, A.V., 2010. Clinical and epidemiological features of opistorhosis in the North-Eastern region of Ukraine. Dissertations for Degree of Master of Science in Infectious Diseases, Sumy State University, Ukraine, 57pp. Available at: http://essuir.sumdu.edu.ua/handle/123456789/4054

Kreptogorskaya, T. A. (1932) Case of opithorchiasis in Kazakhstan. Medical Parasitology and Parasitic Diseases, Moscow, pp 56-63[in Russian].

Kupriyanova, N. Y, Timoshenko, T. M. (2012) Epidemiological characteristics of biohelminthoses in Irkutsk area. Vestnik IrGSCHA, 51, 47-51. [in Russian] Available at: http://vestnik.igsha.ru/vypuski_zhurnala/

Mordvinov, Viatcheslav A., Yurlova, N.I., Ogorodova, L.M., Katokhin, A.V., 2012. Opisthorchis felineus and Metorchis bilis are the main agents of liver fluke infection of humans in Russia. Parasitol. Int. 61, 25-31.

Ogorodova, L. M., Freidin, M. B., Sazonov, A. E., Fedorova, O. S., Gerbek, I. E., Cherevko, N. A., et al. (2007) A pilot scheme of prevalence of atopic states and opisthorchosis and their relationship in people of Tomsk Oblast. Parasitol. Res. 101, 1165-1168

Pantiykhov, A. M. and Vinogradova, L. I. 1963. The Epidemiology of opithochiasis in 
Semipalotinsk Oblast. Works of the Semipalotinsk Medical Institute. Semipalotinsk 1963. pp79-82 [in Russian]

Parkin, D.M., 2006. The global health burden of infection-associated cancers in the year 2002. Int. J. Cancer J. Int. Cancer 118, 3030-3044.

Petavy, A.F., Tenora, F., Deblock, S., Sergent, V., 2000. Echinococcus multilocularis in domestic cats in France. A potential risk factor for alveolar hydatid disease contamination in humans. Vet. Parasitol. 87, 151-156.

Pozio, E., Armignacco, O., Ferri, F., Gomez Morales, M.A., 2013. Opisthorchis felineus, an emerging infection in Italy and its implication for the European Union. Acta Trop. 126, 5462.

R Core Team, 2013. R: A language and environment for statistical computing. R Foundation for Statistical Computing, Vienna, Austria.

Schuster, R., Bonin, J., Staubach, C., Heidrich, R., 1999. Liver fluke (Opisthorchiidae) findings in red foxes (Vulpes vulpes) in the eastern part of the Federal State Brandenburg, Germany - a contribution to the epidemiology of opisthorchiidosis. Parasitol. Res. 85, 142-146.

Shimalov, V., Shimalov, V., 2001. Helminth fauna of the American mink (Mustela vison Schreber, 1777) in Belorussian Polesie. Parasitol. Res. 87, 886-887.

Shimalov, V.V., Shimalov, V.T., Shimalov, A.V., 2000. Helminth fauna of otter (Lutra lutra Linnaeus, 1758) in Belorussian Polesie. Parasitol. Res. 86, 528-528.

Syskova, T.G., Tsybina, T.N., Sidorenko, A.G., Iasinski1̌, A.A., 2001. Parasitic diseases morbidity in the Russian Federation in 1999. Meditsinskaya Parazitol. Parazit. Bolezni 31-35.

Terentyeva, E. K. 1985. A few questions about the epidemiology of opithorchiasis in Pavlodar Oblast. In : Collection of Scientific Papers Questions of Natural Focus of Disease. Almaty: Science 13, 49-54.[in Russian]

Torgerson, P.R., Shaikenov, B.S., Baitursinov, K.K., Abdybekova, A.M., 2002. The emerging 
epidemic of echinococcosis in Kazakhstan. Trans. R. Soc. Trop. Med. Hyg. 96, 124-128.

World Health Organisation, 1991. Basic laboratory methods in medical parasitology. World Health Organisation, Geneva, Switzerland

World Health Organisation, 1995. World Health Organisation Study Group on the Control of Foodborne Trematode Infections: Report of a WHO Study Group, WHO Technical Report Series; 849. World Health Organisation, Geneva, Switzerland.

World Health Organisation, 2010. First WHO report on neglected Tropical Disease. Working to Overcome the Global Impact of neglected Tropical Diseases. Geneva, Switzerland.

Yossepowitch, O., Gotesman, T., Assous, M., Marva, E., Zimlichman, R., Dan, M., 2004.

Opisthorchiasis from imported raw fish. Emerg. Infect. Dis. 10, 2122-2126.

Zhumabekova, B. K. and Kamyeshyeva, G. T. 2008. Parasites of fish from Baikonis Lake: community, ecology and practical significance. Isvestiya (Kazakhstan) Series Biology and Medicine, 3 (267), 3-6. [in Russian] 
Legend for Figures

Figure 1. Numbers of laboratory diagnosed cases of human opithorchiidosis reported in Kazakhstan between 1997 and 2011.

Figure 2. Geographical distribution of human opithorchiidosis in Kazakhstan. Annual incidence of laboratory diagnosed cases per 100,000 between 2010-2011.

Figure 3. Numbers of human cases of opithorchiidosis in Kazakhstan by occupation in 2011 Occupation that could not be specified is given as "other". 


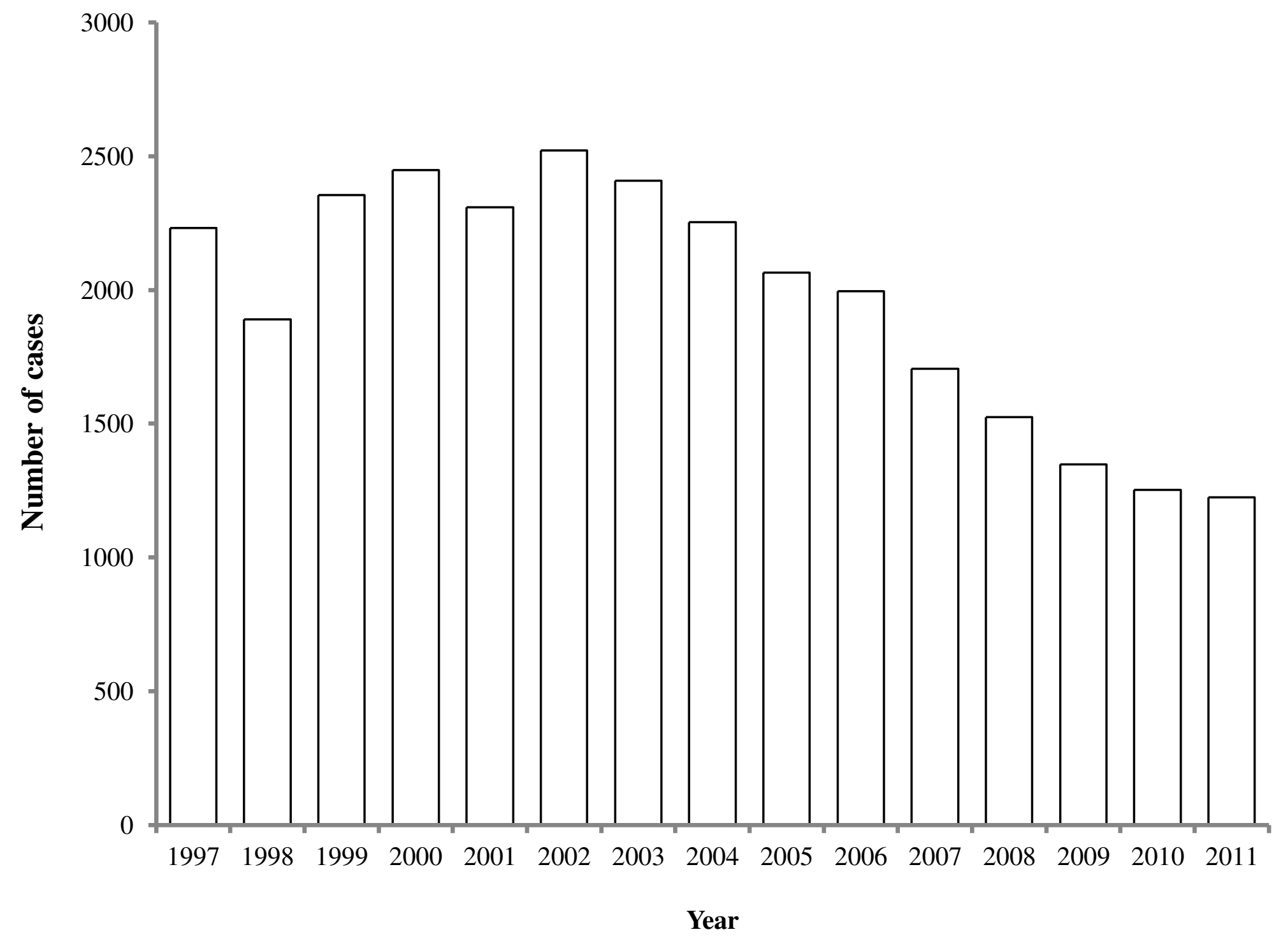


Area for dog, cat and fish studies

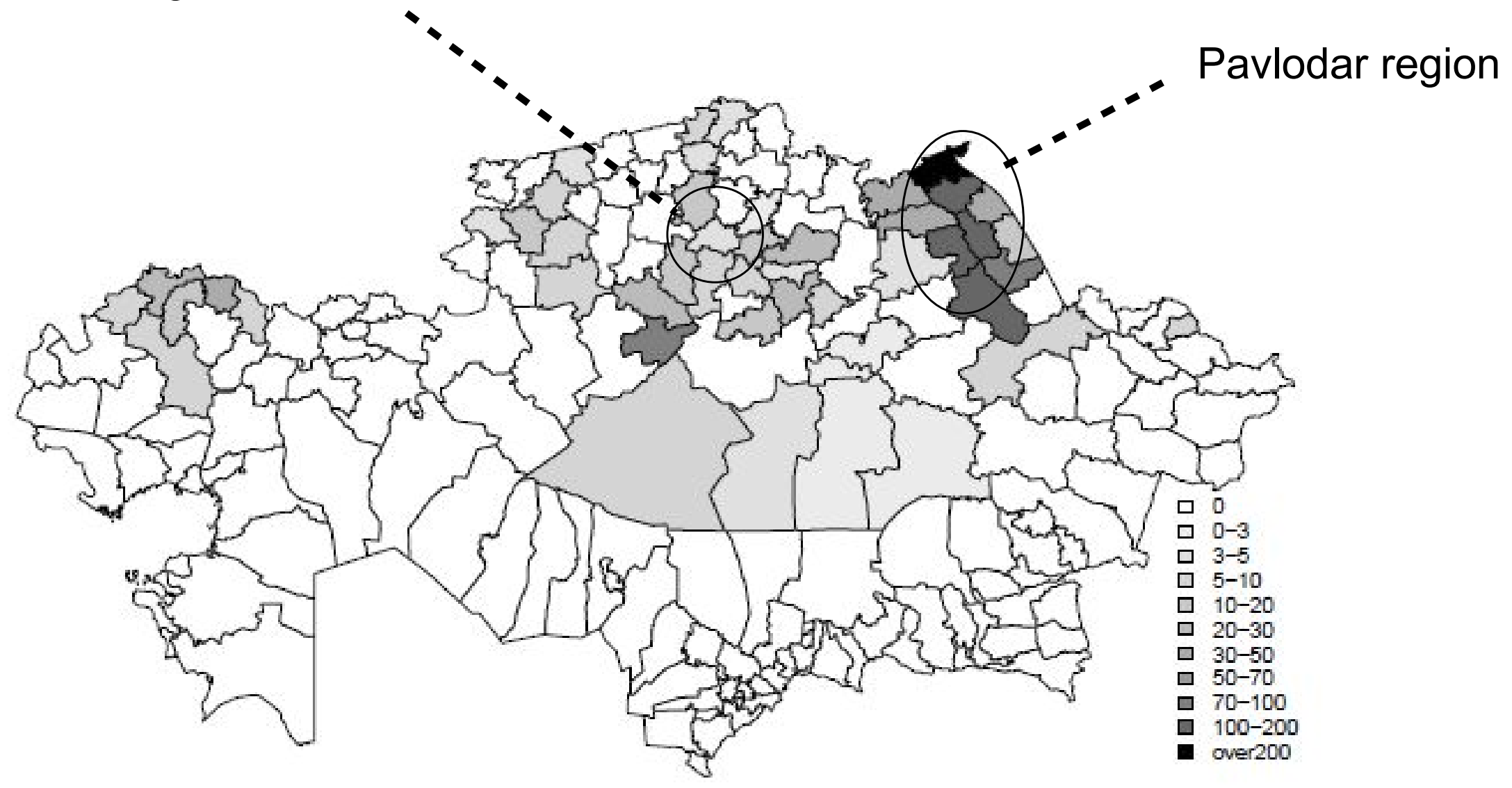




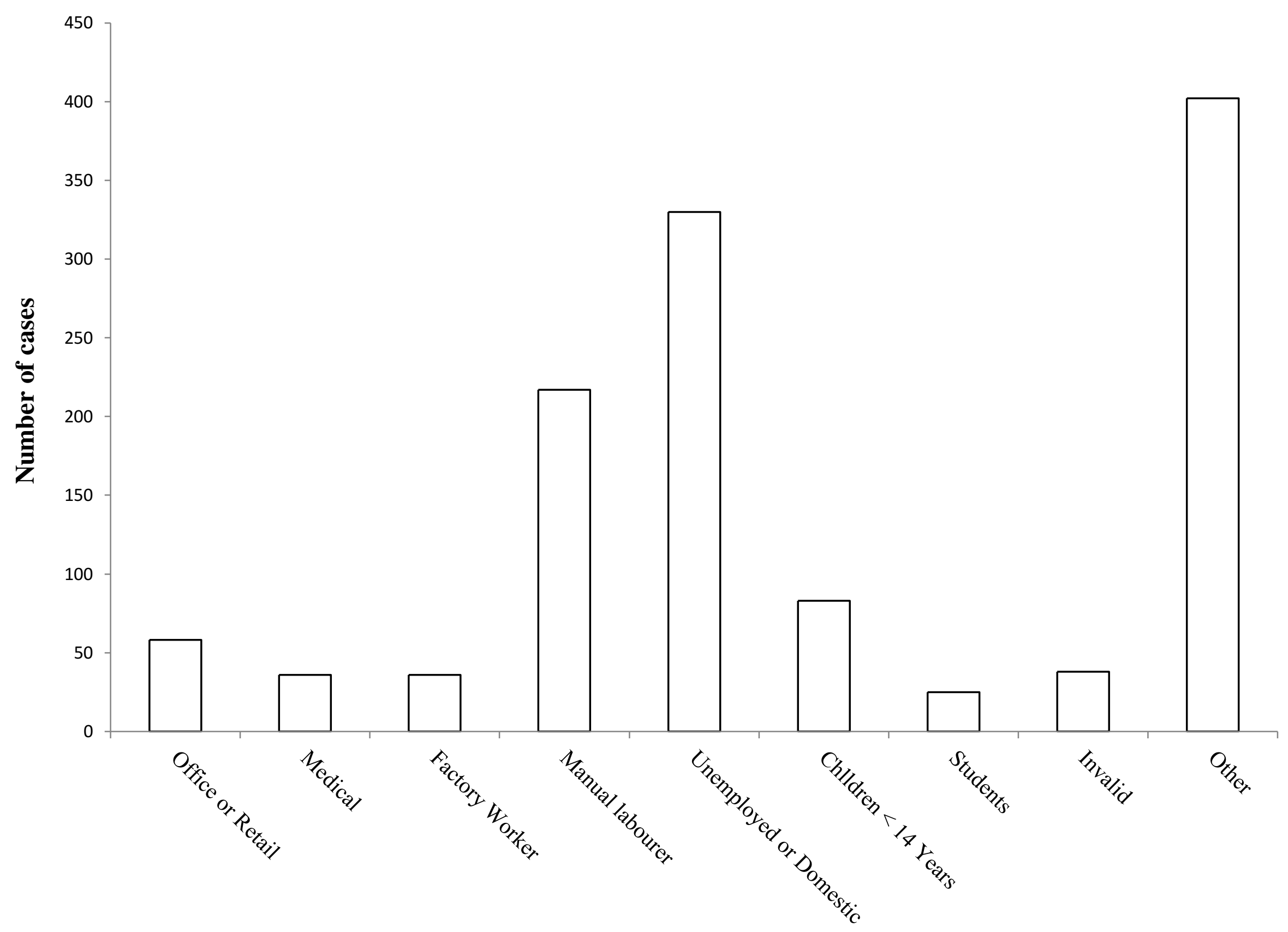


Table 1. Numbers of dogs infected from a sample of 51 village dogs and the abundance of each parasite species found.

\begin{tabular}{lll}
\hline $\begin{array}{l}\text { Parasite } \\
\text { Recovered }\end{array}$ & No. infected & Mean Abundance (confidence intervals) \\
\hline $\begin{array}{l}\text { Dipylidium } \\
\text { caninum }\end{array}$ & 17 & $1.82(0.991-3.81)$ \\
$\begin{array}{l}\text { Echinococcus } \\
\text { granulosus }\end{array}$ & 2 & $3.45(0.496-11.34)$ \\
$\begin{array}{l}\text { Taenia } \text { spp } \\
\text { Toxascaris }\end{array}$ & 3 & $0.078(0.020-0.267)$ \\
$\begin{array}{l}\text { leonina } \\
\text { Toxocara } \\
\text { caninum }\end{array}$ & 15 & $2.00(1.14-3.22)$ \\
$\begin{array}{l}\text { Uncinaria } \text { spp } \\
\text { Methorchis bilis }\end{array}$ & 1 & $5.26(3.74-7.63)$ \\
$\begin{array}{l}\text { Opisthorchis } \\
\text { fileneus }\end{array}$ & 35 & $0.020(0.001-0.086)$ \\
\hline
\end{tabular}


Table 2. Numbers of cats infected and the abundance of each parasite species found

\begin{tabular}{|c|c|c|c|c|c|}
\hline & & \multicolumn{4}{|c|}{ Type of cat and number of cats examined } \\
\hline & & $\begin{array}{l}\text { Cats in city } \\
\text { apartments }(n=25)\end{array}$ & $\begin{array}{l}\text { Cats from the suburbs } \\
(\mathrm{n}=28)\end{array}$ & Village Cats $(n=65)$ & Stray Cats $(n=124)$ \\
\hline \multirow[t]{2}{*}{ Dipylidium caninum } & Abundance & $0.165(0.061-0.437)$ & $4.75(3.36-6.87)$ & $4.31(3.43-5.41)$ & $2.13(1.83-2.47)$ \\
\hline & No Infected & 1 & 22 & 51 & 103 \\
\hline \multirow[t]{2}{*}{ Joyeuxiella rossicum } & Abundance & 0 & $0.616(0.035-2.67)$ & 0 & $0.12(0.037-0.28)$ \\
\hline & No Infected & 0 & 1 & 0 & 4 \\
\hline \multirow[t]{2}{*}{ Echinococcus multilocularis } & Abundance & 0 & 0 & 0 & $2.92(0.440-9.32)$ \\
\hline & No Infected & 0 & 0 & 0 & 2 \\
\hline \multirow[t]{2}{*}{ Taenia taeniaformis } & Abundance & 0 & $4.32(2.97-6.47)$ & $2.17(1.83-2.54)$ & $2.97(2.62-3.40)$ \\
\hline & No Infected & 0 & 21 & 54 & 120 \\
\hline \multirow[t]{2}{*}{ Mesocestoides lineatus } & Abundance & 0 & 0 & $0.231(0.032-0.783)$ & $0.13(0.081-0.212)$ \\
\hline & No Infected & 0 & 0 & 2 & 4 \\
\hline \multirow[t]{2}{*}{ Toxascaris leonina } & Abundance & $1.16(0.81-1.67)$ & 0 & $0.492(0.138-1.21)$ & $0.223(0.083-0.450)$ \\
\hline & No Infected & 5 & 0 & 4 & 6 \\
\hline \multirow[t]{2}{*}{ Toxocara cati } & Abundance & $2.84(1.50-5.34)$ & $6.54(4.61-9.55)$ & $3.49(2.87-4.24)$ & $1.66(1.41-1.95)$ \\
\hline & No Infected & 9 & 24 & 52 & 93 \\
\hline \multirow[t]{2}{*}{ Opithorchis felineus } & Abundance & 0 & $38.2(10.8-92.8)$ & $81.6(50.0-146)$ & $18.2(8.96-46.1)$ \\
\hline & No Infected & 0 & 5 & 44 & 30 \\
\hline
\end{tabular}


Table 4. Parasitic infection of various freshwater fish species

\begin{tabular}{|c|c|c|c|c|c|c|c|c|c|c|}
\hline \multirow[b]{2}{*}{ Species } & \multirow{2}{*}{$\begin{array}{l}\text { Number } \\
\text { Examined }\end{array}$} & \multicolumn{9}{|c|}{ Number infected } \\
\hline & & $\begin{array}{l}\text { Myxosporea } \\
\text { spp. }\end{array}$ & $\begin{array}{l}\text { Microsporidi } \\
\text { a spp. }\end{array}$ & $\begin{array}{l}\text { Diplostomum } \\
\text { sp., larvae }\end{array}$ & $\begin{array}{l}\text { Dilepididae } \\
\text { spp }\end{array}$ & Ligula spp & $\begin{array}{l}\text { Opisthorchiidae } \\
\text { spp }\end{array}$ & $\begin{array}{l}\text { Khawia } \\
\text { sinensis }\end{array}$ & $\begin{array}{l}\text { Philometroides } \\
\text { cyprini }\end{array}$ & $\begin{array}{l}\text { Tetracotyle } \\
\text { spp }\end{array}$ \\
\hline $\begin{array}{l}\text { Crucian carp } \\
\text { Carassius carassius }\end{array}$ & 609 & 34 & 10 & 75 & 11 & 0 & 0 & 0 & 0 & 0 \\
\hline $\begin{array}{l}\text { Roach } \\
\text { Rutilus rutilus }\end{array}$ & 107 & 0 & 1 & 4 & 0 & 2 & 10 & 0 & 0 & 0 \\
\hline $\begin{array}{l}\text { Tench } \\
\text { Tinca tinca }\end{array}$ & 35 & 0 & 2 & 0 & 1 & 0 & 0 & 0 & 0 & 0 \\
\hline $\begin{array}{l}\text { Ide } \\
\text { Leuciscus idus }\end{array}$ & 68 & 0 & 0 & 29 & 0 & 0 & 49 & 0 & 0 & 0 \\
\hline $\begin{array}{l}\text { Carp } \\
\text { Cyprinus carpio }\end{array}$ & 79 & 0 & 0 & 11 & 0 & 0 & 0 & 1 & 1 & 0 \\
\hline $\begin{array}{l}\text { Bream } \\
\text { Abramis brama }\end{array}$ & 79 & 0 & 0 & 15 & 0 & 0 & 2 & 0 & 0 & 1 \\
\hline $\begin{array}{l}\text { Perch } \\
\text { Perca. fluviatilis }\end{array}$ & 46 & 0 & 0 & 3 & 0 & 0 & 0 & 0 & 0 & 0 \\
\hline $\begin{array}{l}\text { Zander } \\
\text { Sander lucioperca }\end{array}$ & 20 & 0 & 0 & 1 & 0 & 0 & 0 & 0 & 0 & 0 \\
\hline
\end{tabular}




\section{Epidemiology of Fish Borne Trematodiasis in Kazakhstan.}

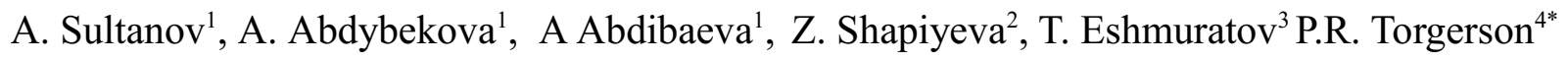

${ }^{1}$ Kazakh State Veterinary Research Institute, Almaty, Kazakhstan

${ }^{2}$ Scientific-Practical Centre for Sanitary-Epidemiological Expertise and Monitoring, Almaty,

Kazakhstan

${ }^{3}$ National Scientific Center of Surgery, Almaty, Kazakhstan.

${ }^{4}$ Section of Epidemiology, Vetsuisse Faculty, University of Zürich, Switzerland

Graphical abstract

Fish borne trematodiasis is an important public health problem in Kazakhstan, particularly in the north of the country.

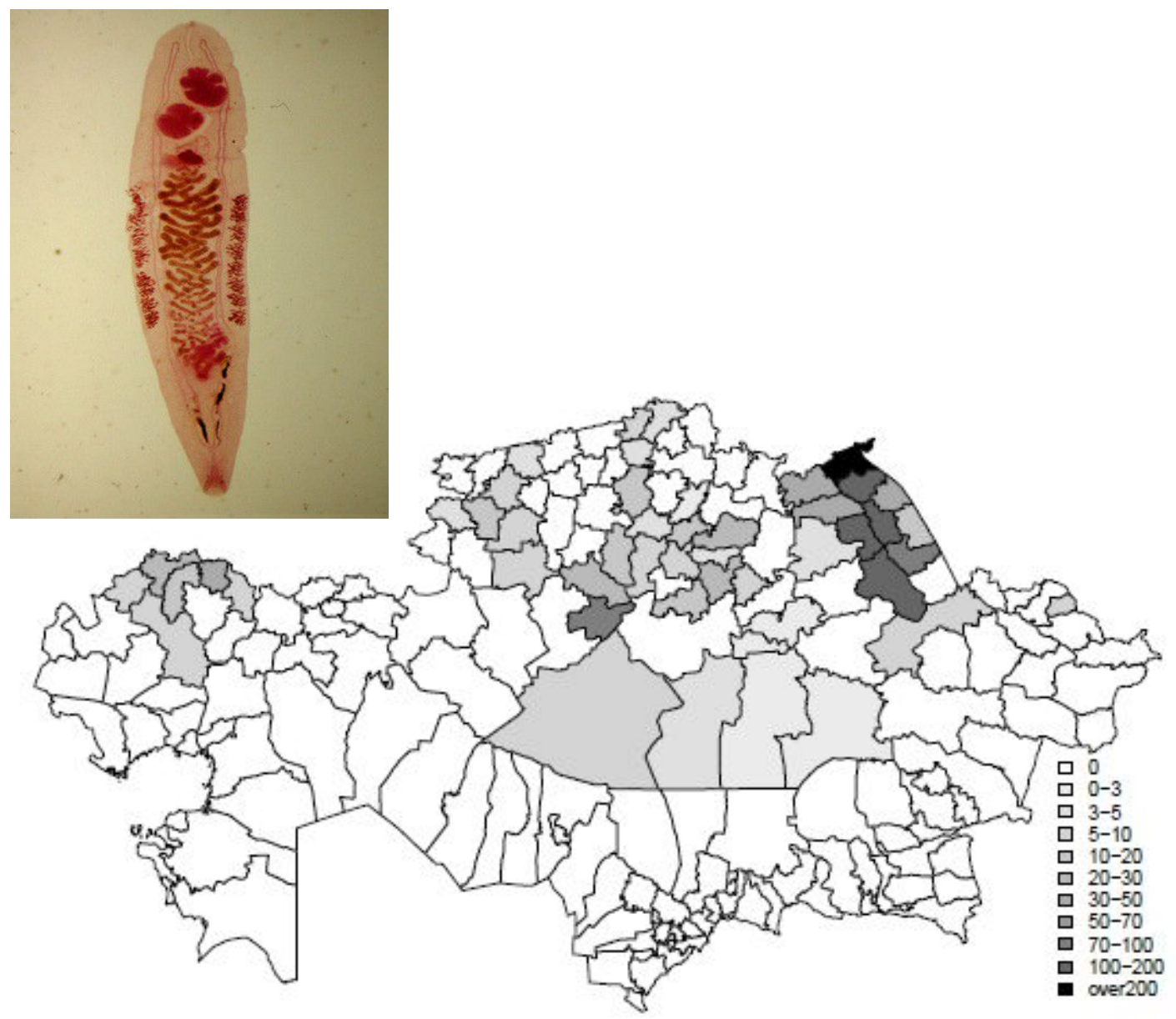




\section{Highlights}

- Fish borne trematodiasis is an important public health problem in Kazakhstan

- Approximately 1200 human cases are recorded each year

- Annual incidences can be as high as 200 per 100,000 in some localities

- Cats and dogs are commonly infected definitive hosts in north Kazakhstan

- Freshwater fish for human consumption are frequently infected with metacercariae 